\title{
Neo ekistics for flood mitigation in cities
}

\section{Structured Abstract}

Purpose - This article sheds light on the potential of ecologically driven urban design interventions to substantiate urban form performance in coping with the increasing flood threats particularly in the Middle East region. This article applies ecological principles to new urban interventions for pluvial flood adaptation in Muscat city, Oman. The interventions incorporate the physical dimensions of both the natural (topography) and the built environment (urban morphology). The study demonstrates different scenarios in Muscat city in Oman and discusses the different challenges faced on different socio-economic and ecological levels.

Design/methodologylapproach - The article adopts a case study approach. The methods include semi-structured interviews aiming to gain insight from experts in the field of study about salient physical interventions to the urban context that are potentially going to help mitigating flood consequences. Mitigation scenarios were guided by the participants' recommendations in the area. Scenarios were tested across two complementary phases using two software packages, the first of which is the pre-processing phase accomplished by using Aeronautical Reconnaissance Coverage Geographic Information System (Arc GIS) and the second is the flood analysis phase done by Hydrological environmental centre for river analysis system (HEC RAS) platform. The scenarios were evaluated in relation to the successfulness and reliability of physical solutions on to which extent the flood wave depth and coverage was reduced.

Findings - The article provides an alternative resilient holistic approach to achieve socially and ecologically sensitive and less expensive flood mitigation solutions in the Middle East.

Originality/value - This article provides a new approach to flood mitigation linking ecological principles to the social dimension of human activities and experience in closely knitted communities.

\begin{abstract}
Climate extreme events have been on the rise over the last few decades. Flooding is one of the dramatic natural hazards leaving behind significant losses. While engineered based solutions are encouraged in flood management frameworks following flood resistance logic, it was found to be incapable of supporting neither long-term solutions nor social restoration. A shift in thinking is required; a new paradigm that calls for a breakaway from the closely confined resistance approach to the concept of living with a tolerated level of water. This is to be realised by carrying out an in-depth analysis of the ecological system services along with the physical aspects of urban design. The process of looking at new alternatives is realised by the fact that existing flood control infrastructures that guaranteed the safety of cities from flood have frequently failed in many places around the world.

This paper sheds light on the potential of ecologically driven urban design interventions in creating urban forms that are capable of coping with the escalating flood threats. This article applies ecological principles to new urban models for pluvial flood adaptation in Muscat city, Oman. The model incorporates the physical dimensions of both the natural (topography) and the built environment (urban morphology). The study demonstrates different scenarios in Muscat city in Oman and discusses the different challenges faced by different stakeholders. Finally, the paper highlights the importance of redirecting efforts and funding towards the perspective of urban resilience as a surrogate approach.
\end{abstract}


Keywords: urban design, ecological compliance, pluvial flood, flood mitigation, urban resilience

\section{Introduction}

The United Nations International Strategy for Disaster Reduction defined a natural hazard as "natural process or phenomenon that may cause loss of life, injury or other health impacts, property damage, loss of livelihoods and services, social and economic disruption or environmental damage". Disasters are the consequences of natural hazards. They are related to the exposure, vulnerability and coping capabilities towards hazards (UNISDR 2009). These factors vary according to the social, economic, geographical and governance characteristics of the place (Banholzer, Kossin, and Donner, 2014).

Flooding, one of the dramatic natural hazards, are highly sensitive to the different levels of warming associated with climate change. It leaves behind significant losses of human lives and damages to properties, habitats, crops, lands as well as infrastructures. Floods also have social, economic and environmental consequences to the affected countries. Many developed and underdeveloped countries have their own flood mitigation and management approaches (Mirza, 2011). Levels of flood risk, history of flood damage, as well as the country's economic advancements defines each country particular approach. The Committee for Development Policy explained that developing countries are those suffering from the severest structural obstacles to sustainable development (CDP, 2011). Although being the least contributors to emitting greenhouse gases; they are also the most vulnerable to climate changes impacts due to their locations, low adaptation and resilience, high population and low resources (Bruckner, 2012; Huq, Reid, Konate, Rahman, Sokona and Crick, 2004). According to Fothergill and Peek (2004), there is a significant relation between the socio-economic status and the physical and psychological consequences of natural disasters. They added that low-income group are the most exposed to physical and psychological losses.

Different forms of flooding exist including the coastal, fluvial, flash, and pluvial flooding (Ashley and Ashley 2007). Houston et al (2011) considered pluvial floods as invisible hazards, being less recognised by the public, and less well understood. Their occurrence is defined as short intense downpours that cannot be managed quickly enough by the drainage system or through infiltration to the ground. The effects of these types of floods are more significant in countries lacking drainage systems for storm waters. With the urban expansion across natural features including streams and flood plains - the positional nature of flood protection infrastructures that are normally positioned in the direction of a clearly defined source of threat, like a river or seaside, make it difficult to deal with this invisible hazard (Houston et al, 2011).

Flood protection measurements and engineering solutions follow similar patterns of thoughts in terms of nature resistance, which is not effective with the increasing extreme climatic events. As a result, cities and their infrastructures are becoming more vulnerable and more threatened. The conventional structures of flood protection are increasingly questioned amongst academics, decision-makers and communities particularly with many cases of failure around the world. Resilience in regional contexts is either theoretical, with a focus on the role of institutions, modelling-oriented, often with a focus on specific subsystems, or aimed at understanding the resilience of economic entities and systems to infrastructure disruption. Meanwhile, the contributions to mitigate or manage flooding in urban areas from within the urban planning discipline involves many aspects including policy making, land use planning, and technically empowered design for urban physical membranes (Chang et al., 2014). Ahern (2011) also mentioned that while adaptive management has been practised successfully in natural resource management for decades, its application to urban planning and design is rare. This adaptation ability, or resilience, is rarely- if never- taken into account in urban policy 
processes. New approaches for characterising the resilience of urban design are urgently needed and worth investing in on both local and regional scales. These approaches are to link urban physical systems with human communities, supporting the information and communication needs of infrastructure organisations, and directly addressing infrastructure decision-making on both urban and regional scales (Chang, et al. 2014). A step change is therefore necessary, particularly in developing countries for a paradigmatic shift from flooding viewed through the lens of flood control to more ecologically driven flood mitigation approach.

\section{Neo ekistics to ecological challenges}

Engineering solutions are usually proposed for flood management frameworks. Although effective as a physical barrier, engineering resilience strategies are unable to support social restoration and recovery. With the rise of the concept of ecology of cities, governments start to shift their current economic domination development strategies to involve environmental values (Elkadi, 2015). Holling (2001) also distinguished between engineering and ecological resilience. This distinction has been later explained by Davoudi (2012) to include the ability and time taken to bounce back to 'normality' as well as the magnitude to absorb disturbances to ecological systems. Liao (2012) added that a new urban resilience to floods is to be developed to address system persistence through changes. He defined this urban resilience as "a city's capacity to tolerate flooding and to reorganize should physical damage and socioeconomic disruption occurs, so as to prevent deaths and injuries and maintain current socioeconomic identity".

Neo Ekistics is an approach to apply ecological principles to urban resilience. Based on Doxiadis's early work of Ekistics, this article takes a holistic approach to urban resilience based on studying the ecological systems of cities as differentiated from ecology in cities (Douglas and James, 2015). Ecology of the city tends to be interdisciplinary and multi-scale, incorporating both ecological and human dimension of the urban ecosystem. Figure (1) exhibits the ecology-of-cities as the position of this study within the spectrum of the ecological paradigms.

Building on the Neo Ekistics approach, this article emphasises the significant need for carrying out in-depth analysis of the ecological system services along with the physical aspects of urban design in flood management frameworks. It incorporates the physical dimensions of both the natural (topography) and the built environment (urban morphology), guided by the social dimension of human experience. 


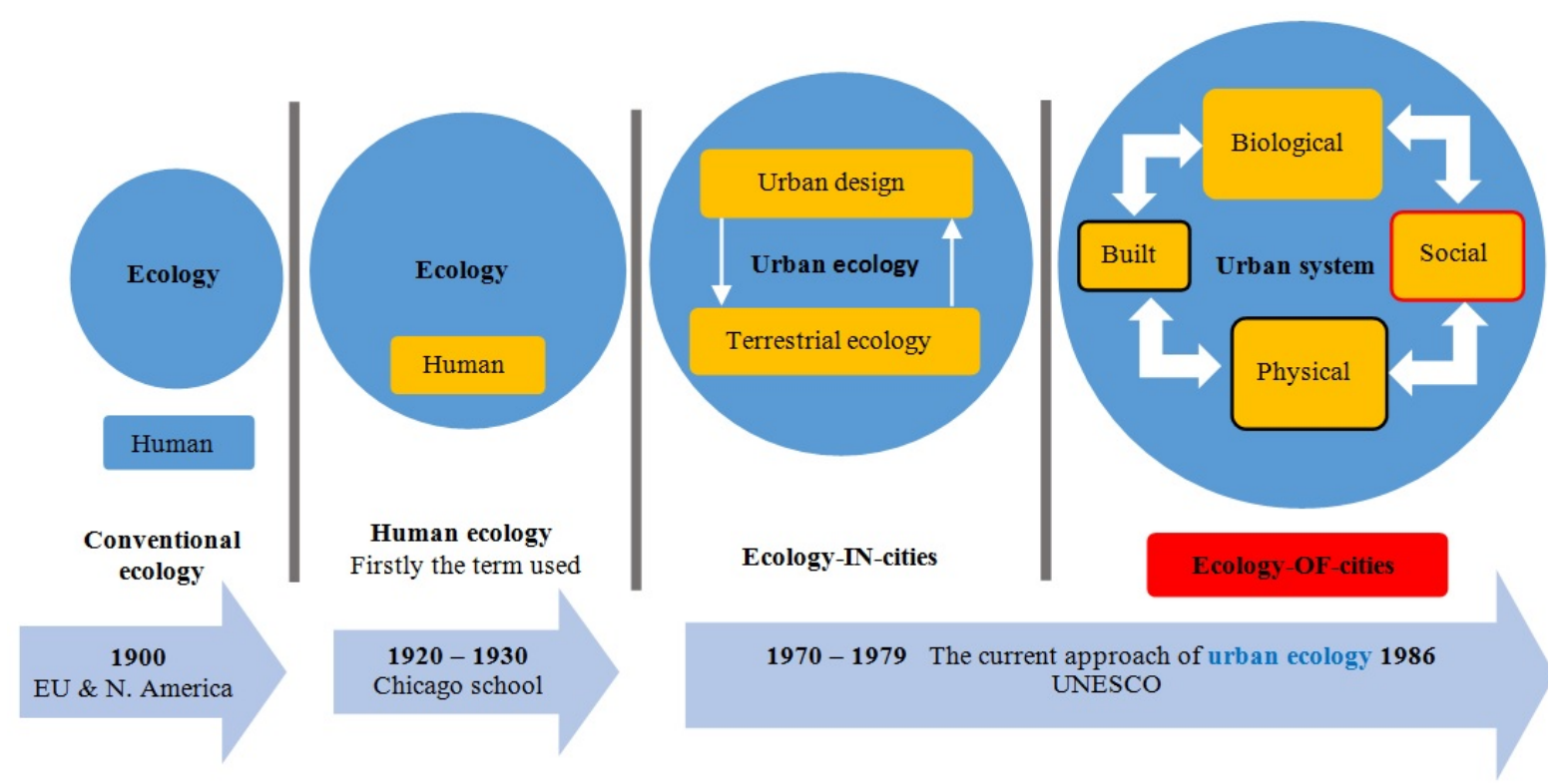

Figure 1: Research position within ecological paradigms $\quad$ (Abdulkareem, 2018)

\section{Study area in natural setting Urbanism and demography:}

This study investigates the flood phenomena in Muscat city; a flood-prone area on seasonal pace. The city is located in north-east Oman at $24^{\circ} 00^{\prime} \mathrm{N} 57^{\circ} 00^{\prime} \mathrm{E}$. Pluvial floods have recently become an increasing phenomenon in Muscat and other cities in Oman. Heavy rainfall, low pressure and tropical storms have affected the city causing fragmented isolated urban areas by stormwater inundation. The area of study (Wadi-Adi), figure (4), witness at least one flood event each year driven from short intense rainfall. There are two distinct manifestations of terrestrial ecology in Muscat city, upon which pluvial floods produce different courses of occurrence. These two are mountainous ecology and the semi-flat hilly areas; the area under investigation resembles the first geo-morphological setting.

Muscat has a hot arid climate with long and very hot summers and warm winters. Annual rainfall in Muscat is about $10 \mathrm{~cm}$ (4 in), falling mostly from December to April. In general, precipitation is scarce in Muscat, with several months on average seeing only a trace of rainfall. However, in recent years, heavy precipitation events from tropical systems originating in the Arabian Sea have affected the city. Cyclone Gonu in June 2007 and Cyclone Phet in June 2010 affected the city with damaging winds and rainfall amounts exceeding 100 $\mathrm{mm}$ (4 in) in just a single day.

Due to the rapid urbanization driven by high demand on new plot of land in the city, figure (2), patch developments along the high ways and aside of linking roads has come to emerge in the urban realm producing more pressure on the urban infrastructure and invading more ecologically critical lands to which the of floods become increasingly evident.

According to the 2010 census statistics, the total population in the study area were about 150,124 forming $19.3 \%$ of the total population of Muscat city. Gender distribution was 57,276 females and 92,848 males. Total of the housing unit was 39,080 forming a percentage of $25.4 \%$ from the total housing units of Muscat city. Total of 32,908 households were occupying the area forming a percentage of $26.9 \%$ from the total households in Muscat city. 

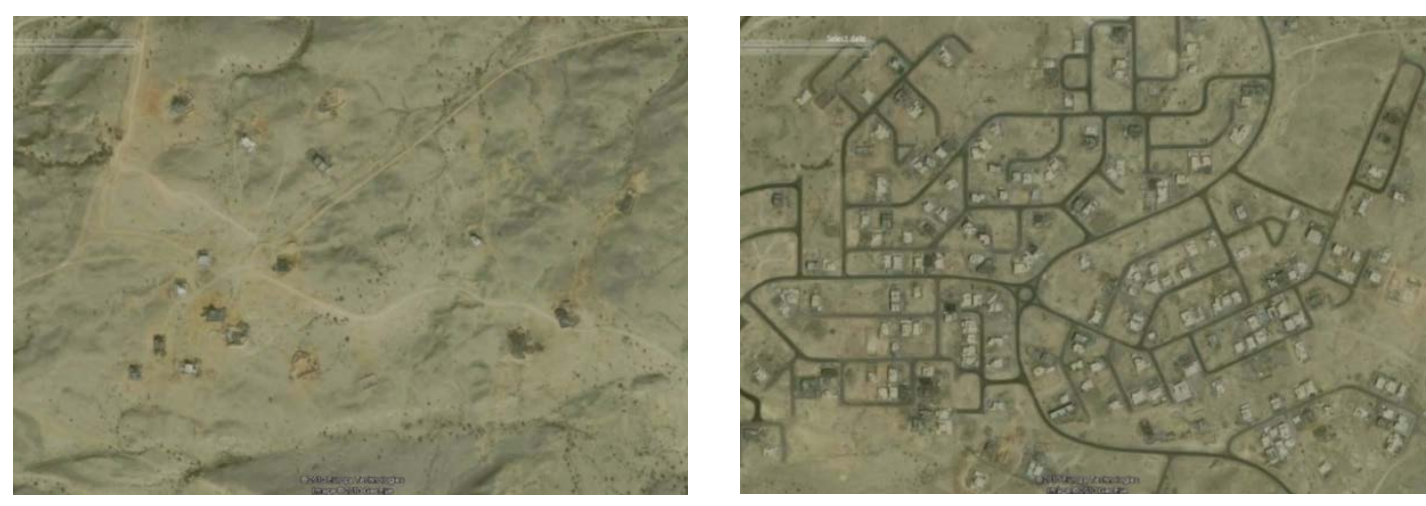

Figure 2 Rapid urbanization between 2001 and 2008 (Al Garibi, 2014)

\section{Methodology}

The paper is addressing the resilience of city to pluvial flood from within the field of urban design. A case study analysis can provide rich explanations that are required for an interpretive study (Miles \& Huberman, 1994). Muscat case provided extensive data, relevant to its particular context. As a result, two areas in the city were selected to explore the problem and potential physical solutions and to provide in-depth information needed to understand the underlying factors that construct the flood phenomena in Muscat. The criterion by which the case study areas were selected originated to one reason and two factors. The reason was that both areas were notorious flood-prone areas with concurrently flooding incidents each year. They both catch stormwater in a form of large ponds and each heavy rainfall event leads to a whole local urban system shutdown. The first factor is socially driven, as both areas were relatively old parts of the city, densely populated, with a low ratio of urban open spaces. The second factor is a physical topographically driven factor, as both areas are located within one topographic area with natural distinction and variety, a combination of flat and rough terrain that allows enough room to apply physical intervention for flood mitigation scenarios.

Mixed methods were employed, starting with a qualitative analysis, followed by quantitative analysis where numerical data of precipitation were introduced to the software in the context of physical intervention. Qualitative and quantitative forms of data were collected in the field at the sites where participants' experience flooding. This up-close information gathered from participants, including face to face interviews, in their actual context was necessary for qualitative research (Creswell, 2007).

The interpretive perspective is used to understand the meaning and interpretation of the phenomena and solutions developed from selected participants through a semi-structured interview. A stratified sample of 16 participants was selected for the case study areas; participants were coming from different background divided between the public sector, private sectors and academia. Selection strategy, consent forms and interview protocol were considered. The main aim of the interviews was to gain insight from experts in the field of study about salient physical interventions to the urban context that are potentially going to help mitigating flood consequences. The unit of morphological analysis of the urban forms was developed from Conzen's analysis for the urban morphology. Streets, plots and buildings were the three main units of morphological analysis used to identify the selected area, figure (3).

These physical interventions facilitate building mitigation scenarios. Interviewees included managers, urban planners, architects, and hydrologists were well aware of the area and the previous projects implemented to avoid flooding problems. The variety of expertise helped in capturing different perspectives and stances, which improves the outcomes. The data analysis revealed themes that were used to build the discussion with participants in each context. 


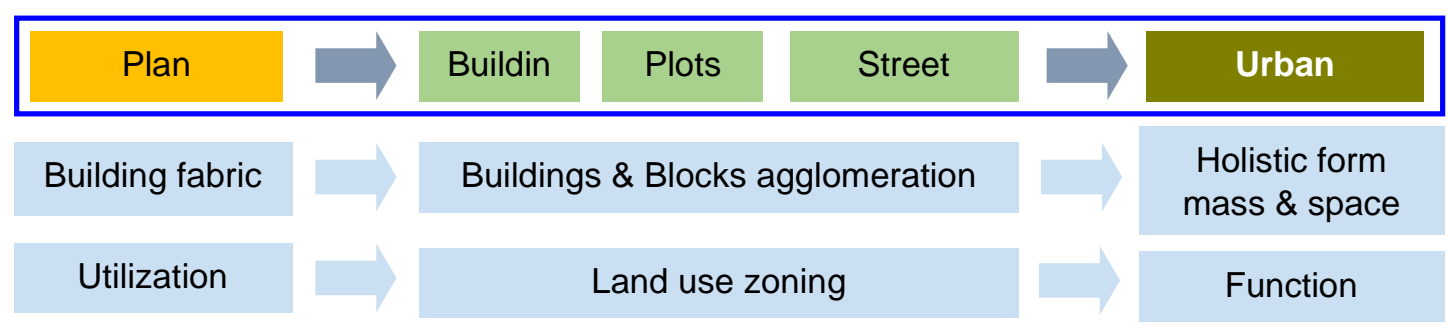

Figure 3 Urban morphological components (Abdulkareem, 2018 adopted from Conzen, 1960)

The qualitative part of this research, namely the interviews, forms the major contribution to the data collection; however, the quantitative part that follows helps to identify influential variables from the qualitative inquiry. Mitigation scenario building was guided by the participants' recommendations in the area. Scenarios were tested across two complementary phases the first of which was the pre-processing phase and the second for the analysis phase. Arc GIS was used for pre-processing the digital data. Meanwhile, the HEC RAS platform was used subsequently to simulate flood conditions before-and-after introducing physical intervention. Results were evaluated in relation to the successfulness and reliability of these physical solutions reflected mainly in flood propagation reduction.

After collecting and analysing qualitative data from interviews, quantitative data were deployed to test the physical variables in table (1). This was conducted through allocating selected physical variables that resulted from the qualitative analysis into a real-world situation test. The intervention scenarios were built by combining these selected physical variables and the quantitative data of the existing situation including the topographic data represented by the digital elevation, (the height of each pixel of the geo-referenced image in millimetres) of the selected areas along with the time series of the rainfall readings of the storm event (inundation depths in millimetres).

\section{Case-content Analysis}

Insights gained from respondents on the case under investigation were analysed and revealed a number of influential variables. Those variables framed a road map to physical interventions in the study area. The results were presented in Table (1) in a hierarchal order of importance from general to specific as, themes, factors, and relevant variables.

\begin{tabular}{|c|c|c|c|}
\hline Themes & Factors & Variables & Description \\
\hline \multirow{4}{*}{$\begin{array}{l}\text { Building - space } \\
\text { ratio }\end{array}$} & $\begin{array}{l}\text { Within plot building- } \\
\text { space ratio }\end{array}$ & Overexploitation prohibition & Legislative dimension (non-physical) \\
\hline & $\begin{array}{l}\text { Within block building } \\
\text {-space ratio }\end{array}$ & Space interconnectedness & Allow for sufficient open space. \\
\hline & \multirow[t]{2}{*}{ Building-space order } & Flow pathways & $\begin{array}{l}\text { Organise building-space order to create } \\
\text { pathways }\end{array}$ \\
\hline & & Space natural compliance design & $\begin{array}{l}\text { Design for effective, flow enabling space } \\
\text { linkages }\end{array}$ \\
\hline \multirow{4}{*}{ Plot idealisation } & \multirow[t]{2}{*}{ Urban design level } & Horizontal space flow & $\begin{array}{l}\text { Design in compliance with natural flow } \\
\text { pathways }\end{array}$ \\
\hline & & Collective plot order & Consider the overall plot cluster geometry \\
\hline & \multirow{2}{*}{ Building level } & Horizontal obstacle & \multirow{2}{*}{$\begin{array}{l}\text { Horizontal-vertical permeability on the plot } \\
\text { level }\end{array}$} \\
\hline & & Vertical obstacle & \\
\hline Urban design & Urban typology & Linear layout & Topographically compliant Linear layout \\
\hline \multirow[b]{2}{*}{ Transportation } & \multirow{2}{*}{$\begin{array}{l}\text { Geo-responsive } \\
\text { design }\end{array}$} & Gradient-parallel & Transportation routes runs gradient-parallel \\
\hline & & Elevation responsive & $\begin{array}{l}\text { Route alignment ultimately trails higher } \\
\text { elevation }\end{array}$ \\
\hline \multirow{5}{*}{$\begin{array}{l}\text { Man-made } \\
\text { measurements }\end{array}$} & \multirow{2}{*}{$\begin{array}{l}\text { Eco-compliant } \\
\text { design }\end{array}$} & Path dependency & $\begin{array}{l}\text { Design to avoid or comply with natural } \\
\text { pathways }\end{array}$ \\
\hline & & Flow facilitating spatial order & $\begin{array}{l}\text { Design to facilitate flow between natural } \\
\text { points }\end{array}$ \\
\hline & \multirow{3}{*}{$\begin{array}{l}\text { Intervention } \\
\text { hierarchy }\end{array}$} & Reliable intervention & $\begin{array}{l}\text { Geometric alteration on the single urban unit } \\
\text { shape, direction and/or elevation }\end{array}$ \\
\hline & & Costly retrofitting & Remedial building- space creation/alteration \\
\hline & & Liable evacuation & Prone buildings clearance- land use shifting \\
\hline
\end{tabular}




\begin{tabular}{|c|c|c|c|}
\hline \multirow{6}{*}{$\begin{array}{l}\text { Natural } \\
\text { characteristics }\end{array}$} & \multirow[t]{2}{*}{ Within W.S qualities } & Upstream-downstream location & $\begin{array}{l}\text { Initial runoff generation locations versus final } \\
\text { runoff accumulation locations }\end{array}$ \\
\hline & & Within W.S gradient & Within W.S contour lines index \\
\hline & \multirow[t]{2}{*}{ Cross W.S qualities } & Cross W.S gradient & $\begin{array}{lll}\begin{array}{l}\text { Overall natural gradient } \\
\text { watersheds }\end{array} & \text { connecting } \\
\end{array}$ \\
\hline & & Cross W.S linkages & $\begin{array}{l}\text { Natural Accessibility points between } \\
\text { watersheds }\end{array}$ \\
\hline & \multirow{2}{*}{$\begin{array}{l}\text { Eco-services } \\
\text { restoration }\end{array}$} & W.S rehabilitation & \\
\hline & & Stream restoration & \\
\hline \multirow{4}{*}{ Occupants } & \multirow{2}{*}{ Occupants type } & Vulnerable & \multirow{4}{*}{ Planning dimension (non-physical) } \\
\hline & & Manageable & \\
\hline & \multirow{2}{*}{ Occupants mode } & Permanent & \\
\hline & & Temporal & \\
\hline \multirow{2}{*}{ Accessibility } & \multirow{2}{*}{ Emergent needs } & Food \& water & \multirow{2}{*}{ Logistic aspect (non-physical) } \\
\hline & & Health services & \\
\hline \multirow{2}{*}{ Location } & \multirow{2}{*}{$\begin{array}{l}\text { Downstream prone } \\
\text { areas }\end{array}$} & Desensitized uses & Planning dimension (physical related) \\
\hline & & Low occupancy rate & Land use related variable \\
\hline \multirow{4}{*}{ Essentiality } & \multirow{2}{*}{ Land use } & Redundancy & Planning dimension (physical related) \\
\hline & & Absorbency & Water retention enabled design \\
\hline & \multirow{2}{*}{ Economic value } & Physical assets & Planning dimension \\
\hline & & Disturbance-related loses & Economic aspect (non-physical) \\
\hline
\end{tabular}

Table 1 Physical Intervention Variables

The validity and robustness of both qualitative and quantitative analysis were applied in multiple attempts. A pilot interview with three participants was performed to check the clarity and effectiveness of the interview questions. This helped to shape the questions in a way to more effectively approach the problem under investigation. Also, results from the content analysis were sent back to all participants along with a form of satisfaction and suggestions, accordingly, feedback from participants was satisfactory and the framework of physical variables in table (1) was very well received.

While the validity of the quantitative analysis was done by comparing simulation results with the existing flood readings. There was a marginal variation between the real situation and the simulation results ranges from $(7-15) \mathrm{cm}$. This was marginal, taking the maximum flood depth in the area of (2.7) $\mathrm{m}$. Also, the appropriateness of the selected physical variables and the building of the intervention scenarios were shared with participants effectively.

\section{Mitigation scenarios and discussion}

Flood simulation is used to enable comparison between different flooding scenarios. The two intervention scenarios were based on the selected variables obtained from the semi-structured interviews. The scenarios are associated with upstream-downstream flow conditions and urban retrofitting.

The current urban and natural settings of the Wadi-Adi catchment are simulated against the flood event of June 2007. The tropical cyclone, Gonu, severely affected the area; its impact was one of the worst across Muscat in terms of flood depth as shown in figure 4. 

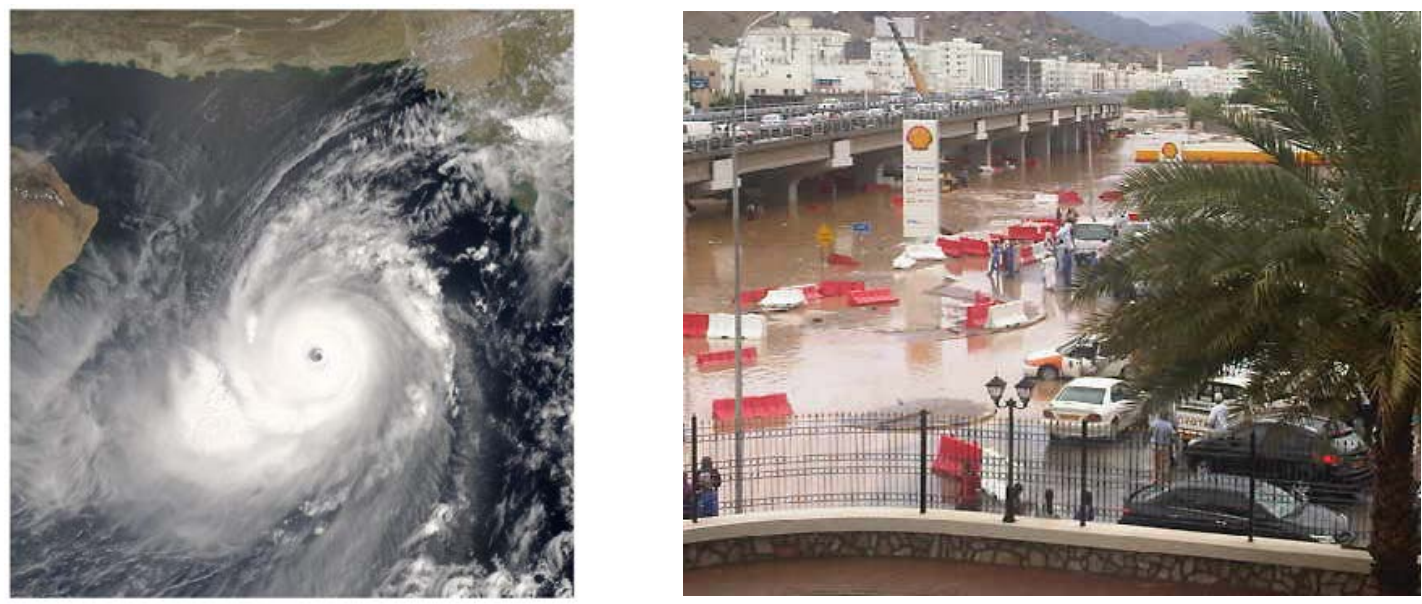

Figure 4 Tropical cyclone Gonu 2007 in Wadi-Adi catchment (google.com)

For the purpose of the flood analysis, the Digital Elevation Model (DEM) layer of the study area was elaborated to match the existing settings. The DEM layer is the best available source that incorporates digital elevation readings for urban and natural surfaces. A digital terrain model (DTM) was not readily available. Hall and Rowsell, (2011) also confirmed that modern flood risk management no longer relies solely upon engineered flood defence structures, such as dykes, channel improvement works, and barriers. Accordingly, a 'set-to-original' approach was employed to restore natural topography in its original setting before urban encroachment. Urban enhancement was also confirmed by White, (2008) who stated that resilience approaches should not be considered late with structural and non-structural solutions, but rather than originate from within the core of the urban planning process.

This lengthy process, using Arc GIS raster analysis tool, ensured precision results with reliable outcomes compared with real flood readings taken from a previous storm event. The storm readings of precipitation and inundation were acquired from the Ministry of regional municipalities and water resources (MRMWR) in Muscat. Areas circled in Figure 8 refer to the locations where a necessary topographic rectification was made

The existing situation of the urban setting, along with natural topographic features, were introduced to the HEC RAS (Hydrological Environmental Center for River Analysis System) platform to simulate the current flood situation. precipitation and natural stream flow readings were devised in the software simulation engine. A combined module of rain and river flow was created to build the status-quo conditions for the purpose of later comparisons.

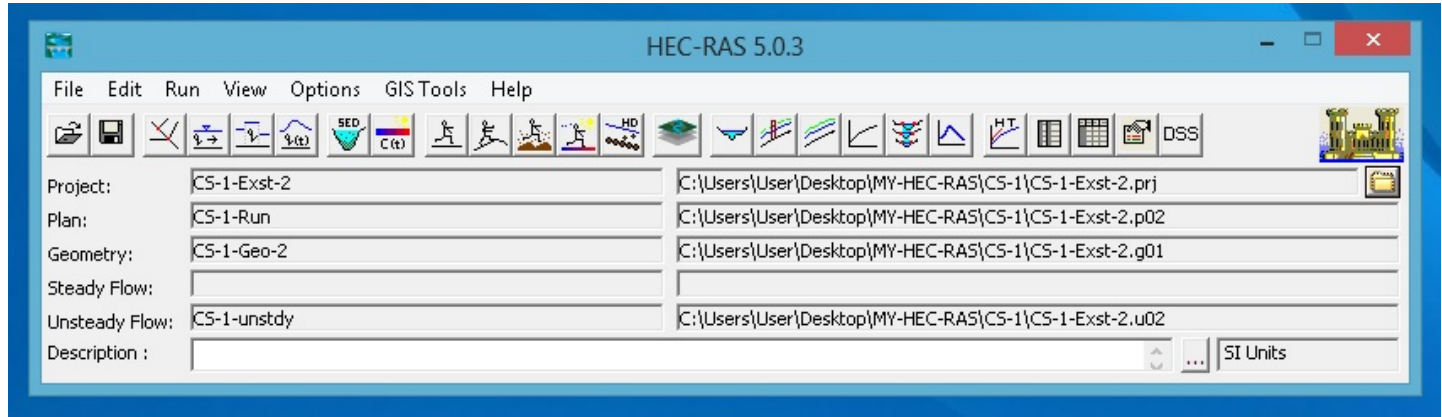

Figure 5 HEC RAS platform for the existing situation

A profile line was assigned along the affected corridor depicting the peak event as shown in figure 6. A combined model of rainfall data and natural stream flow was built in HEC RAS platform, figure 5. The module simulated an unsteady flow resulting from 24.5 hours of convective rainfall in the study area. The extent of the flood wave depth and coverage across 
the event period, mentioned above, was revealed. The profile line shows the levels to which runoff depth and coverage arrived. The area between $0.24 \mathrm{~km}$ and $0.6 \mathrm{~km}$ in figure 6 was heavily susceptible to inundation. Maximum depth of around 2.85 metres was recorded as a peak flood depth at some point on this part of the main street corridor. Meanwhile, the real reading taken from the ground at that time was 2.7 metres at the same location. The result from the simulation is 0.15 meters less than real measures recorded in 2007. this is the best result produced after calibrating the simulation in the three different mesh resolutions at HEC RAS. However, it is higher than the readings extracted from the real situation. Although this can affect the precision of the simulation, it can arguably reflect an implicit 0.15 metres less than the reduction in water depth when applying the mitigation scenario. Figures 7 outlines the existing situation compared to the full flood peak at the end of the event.

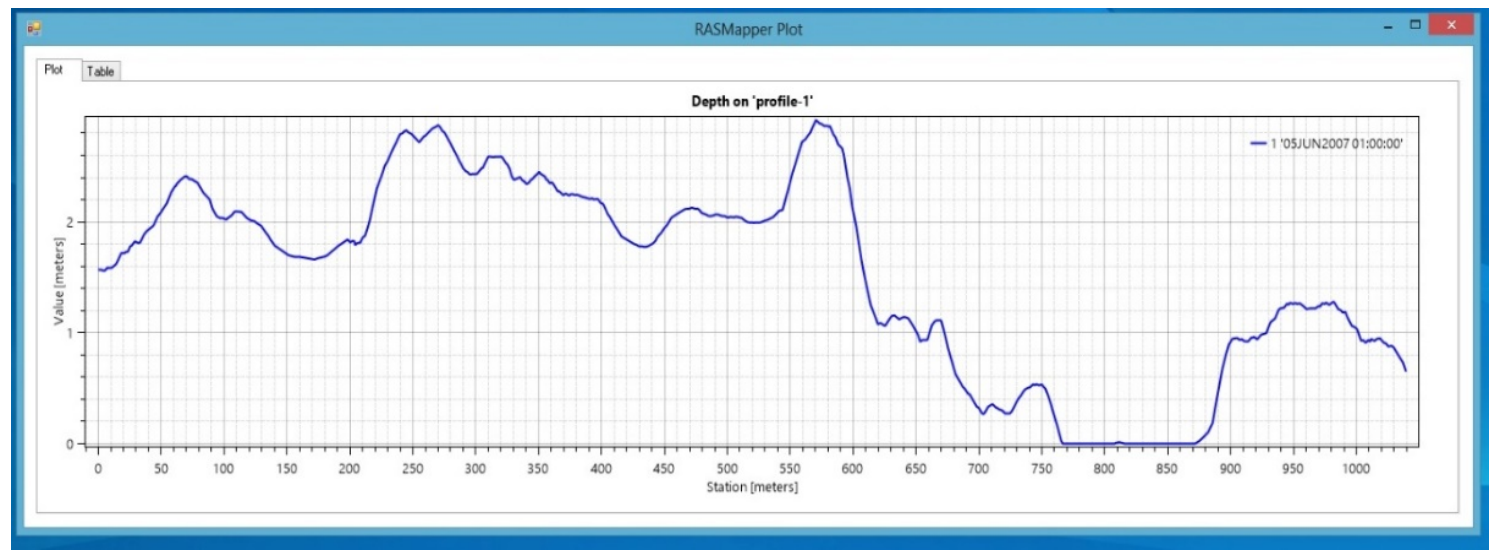

Figure 6 existing situation-profile line on the prone corridor

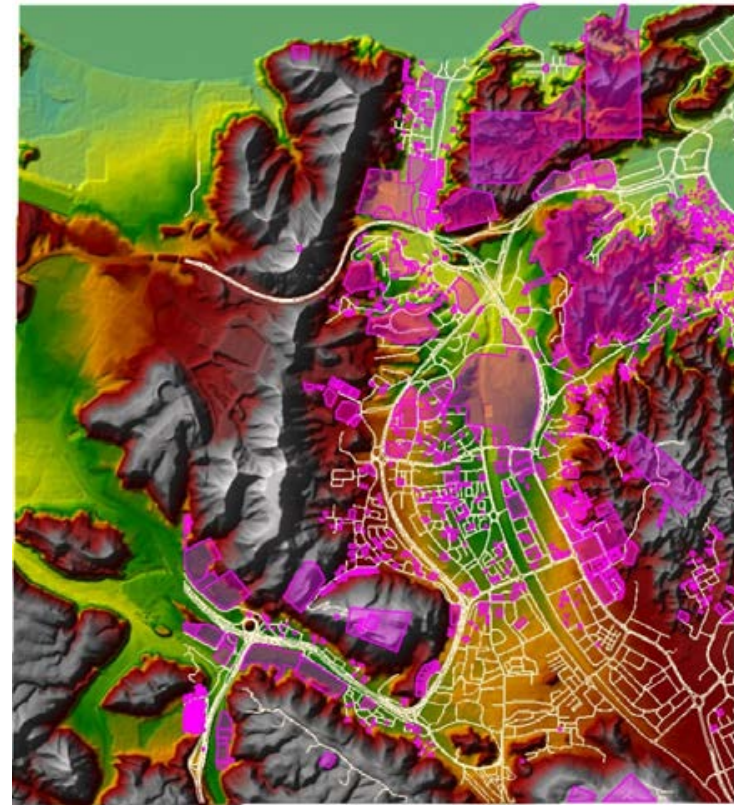

(a)

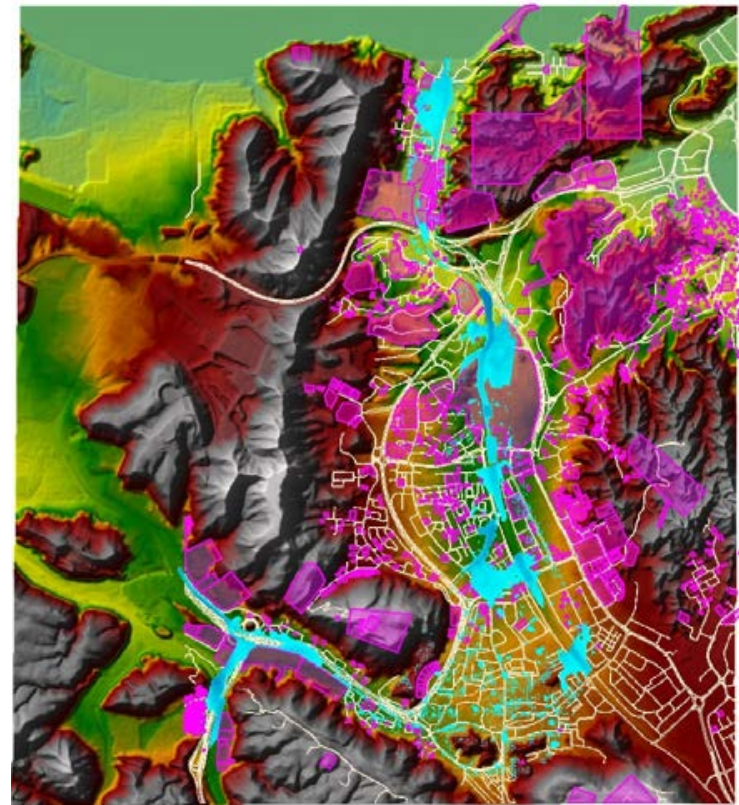

(b)

Figure 7 The studied area before (a) and after (b) the event conditions

\section{Scenario one:}

There is a need for methods to characterise infrastructure resilience in applied, real-world contexts, based on the limited information at hand regarding performance in extreme events (Chang, et al., 2014). The physical intervention in this scenario targeted an important 
intersection in the prone area, shown in figure 8, at which runoff readings were the highest recorded by (MRMWR). The problem of flood inundation initiated almost one kilometre before that intersection, on the main road approaching the intersection from Al-Amerat district. The location significantly involves traffic diverging into two main directions and one local route. Areas (a) and (b) on Figure 8 respectively delineate a boundary of maximum inundation depth and an ecologically critical area with a natural stream pathway that has been disturbed and diminished under urban encroachment. In this perspective, Zevenbergen (2011) confirmed that Cities experience a growing challenge, which is represented in two ways; the intensification of storm events associated with climate change, and the increase in the urban development.

A major project was implemented in the area 2012; as a combined solution of one flyover, converting the existing roundabout into signalised intersection and box culverts improvement. After full implementation, the problem of traffic congestion reduced significantly, opening free connection routes to the rapidly expanding Al-Amerat residential area. Yet, the project lacks a proper understanding of the ecological setting in the area.

The problem of the inundation was witnessed frequently after the recent major works mentioned above were carried out. This is a result of solely relying on protection infrastructure and less importance is given to handling the delicate ecological settings. Expanding the urban development of buildings, roads, and sealed surfaces blocked the connection continuity of a major stream running across the area. This changed the watershed characteristics and led to an exacerbation of the problem. In this sense, Ning (2006) confirmed that exclusive dependence on flood-control works is insufficient and falls short of the objectives of reducing losses.

The development of scenario one stemmed from three influential variables, represented on two morphological levels; generated-morphology and geomorphology. It generally followed natural rehabilitation and urban evacuation. The rehabilitation process involved maintaining a vital link for the natural stream's disrupted sides. This was achieved by removing the encroachment of road and building developments. The three influential variables from two morphological levels applied in this scenario are displayed in Table (2).

\begin{tabular}{|c|l|l|}
\hline \multicolumn{2}{|l|}{ CS-1 scenario one variables and reflections } \\
\hline Variables & Variable orientation & Variable manifestation \\
\hline $\begin{array}{l}\text { Natural stream } \\
\text { restoration }\end{array}$ & Geomorphology & $\begin{array}{l}\text { Natural stream rehabilitation by } \\
\text { maintaining a vital link connection. }\end{array}$ \\
\hline $\begin{array}{l}\text { Flow pathways } \\
\text { space design with } \\
\text { natural flow } \\
\text { pathways }\end{array}$ & $\begin{array}{l}\text { Generated } \\
\text { morphology }\end{array}$ & $\begin{array}{l}\text { Building evacuation. } \\
\text { - Secondary road removal } \\
\text { (Alternatively elevated by culverts) }\end{array}$ \\
\hline
\end{tabular}

Table 1: Influential variables for scenario one 


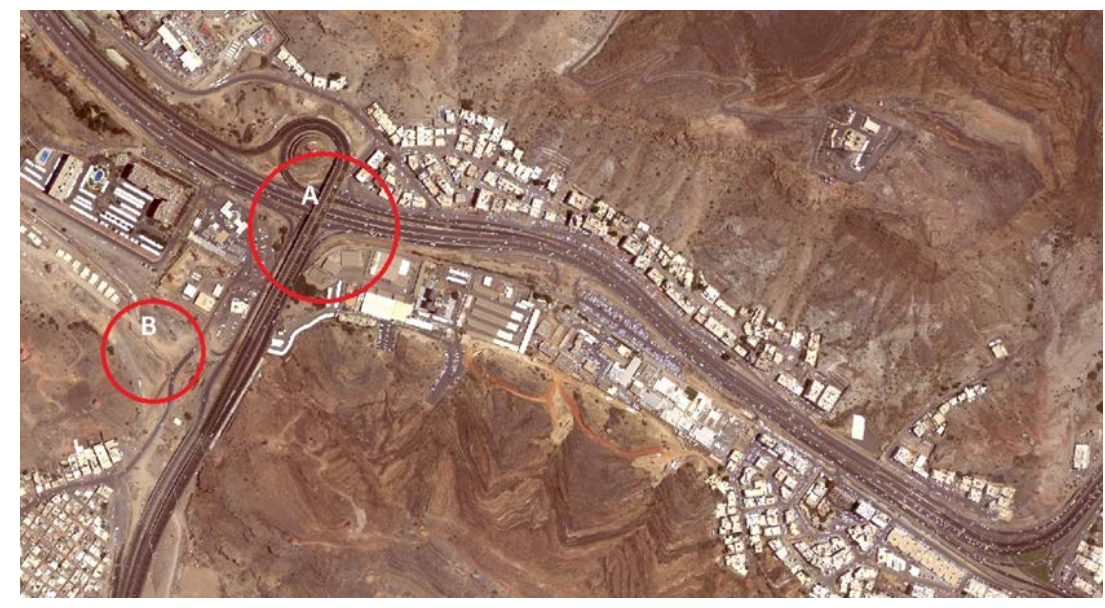

Figure (8) Study area catchment

The physical intervention for scenario one was introduced to the HEC RAS platform, to simulate the current flood situation. Data for rainfall readings and the natural stream flow were added to the software simulation engine. A combination of the rain and streamflow module was created to build the status-quo conditions for the purposes of later comparisons.

A combined model of rainfall data and natural stream flow was built in the HEC RAS platform. In this scenario, the profile line aligned along the affected corridor depicting the peak of the event shows the levels to which runoff depth and coverage arrived. As shown in figure 9 the extent of the flood depth and inundation coverage area was significantly reduced on the main corridor.

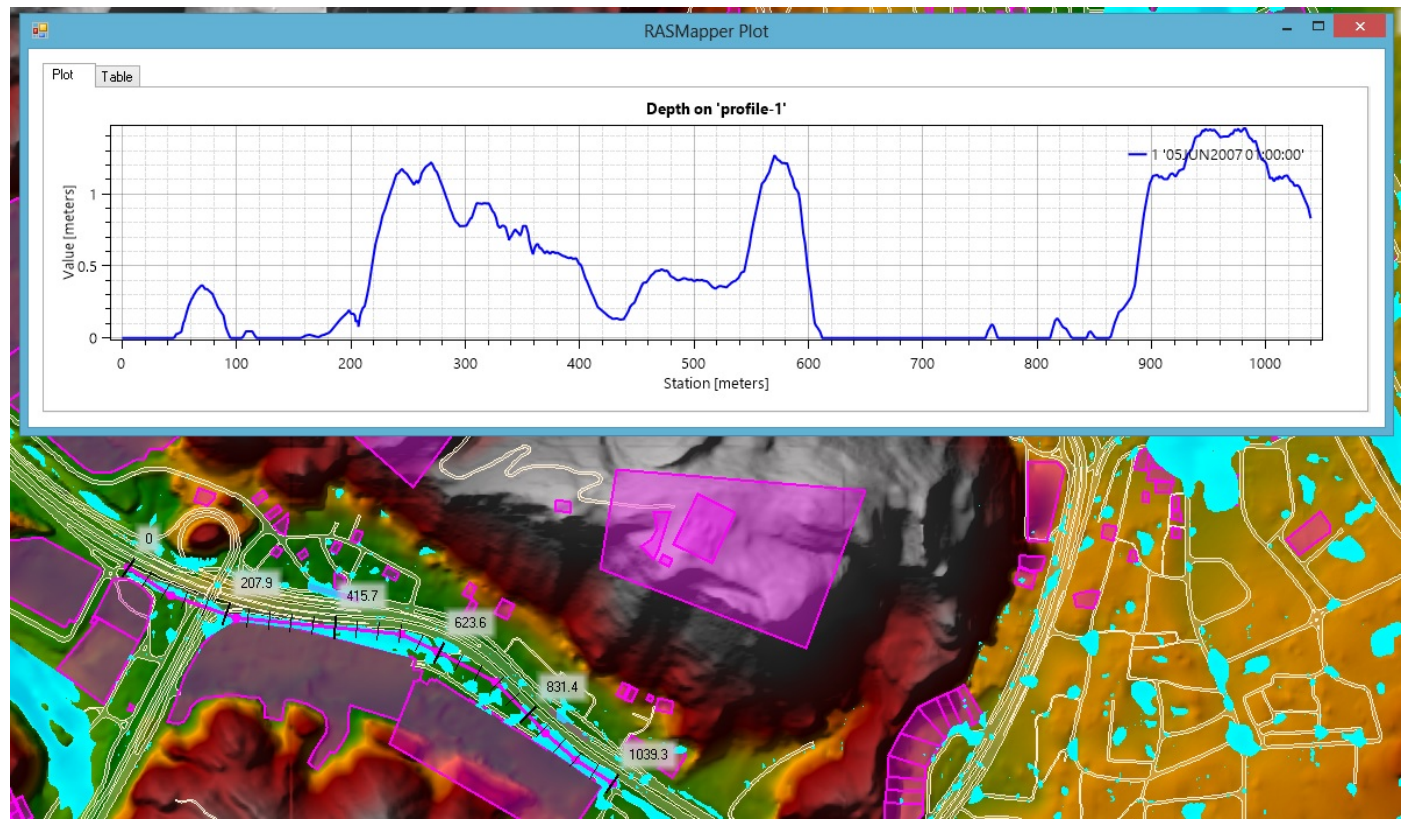

Figure 9 HEC RAS platform for scenario one

Maximum depth of around 1.4 metres was recorded as a peak runoff depth, but at the bottom of the surface, runoff channelisation shown in figure 11 . However, this scenario involved a few building evacuations and a mosque. It was essential to completely clear the natural stream path and eliminate any chance of flood exposure for buildings or vulnerable individuals. Aside from the compensation cost, there were some socio-cultural challenges associated with religious buildings, especially in vernacular areas, like Wadi Adi. This scenario is quite challenging for decision-makers particularly with extensive experience and successful practice 
in compensating both individuals and other commercial parties. Figures 10 shows the situation compared to the full flood peak at the end of the event with the physical variables from table (1) in place. Runoff velocity check for all scenarios showed no significant runoff velocity that could be taken as a risk factor in the area.

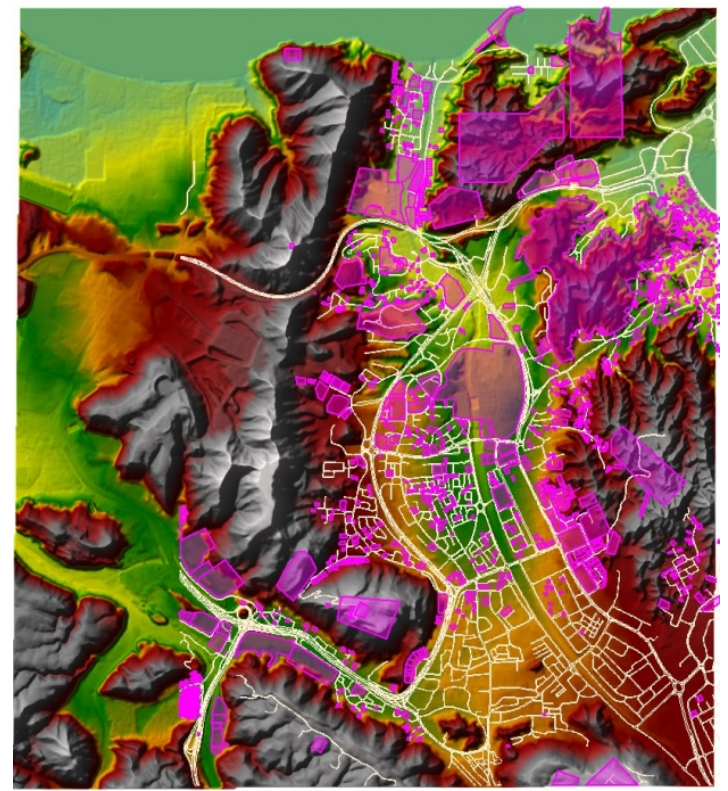

(a)

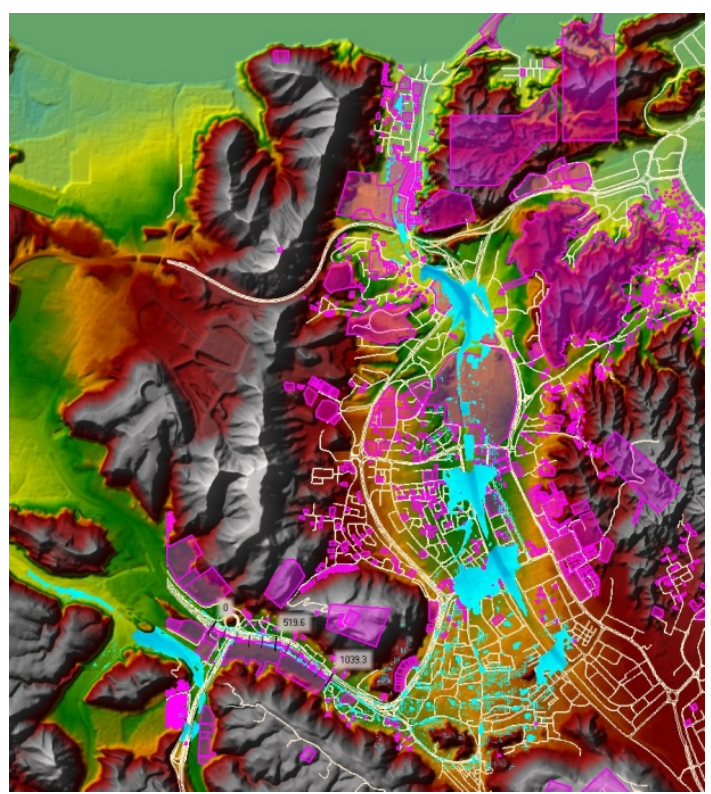

(b)

Figure 10 Case study area (a) existing condition and (b) full flood event condition

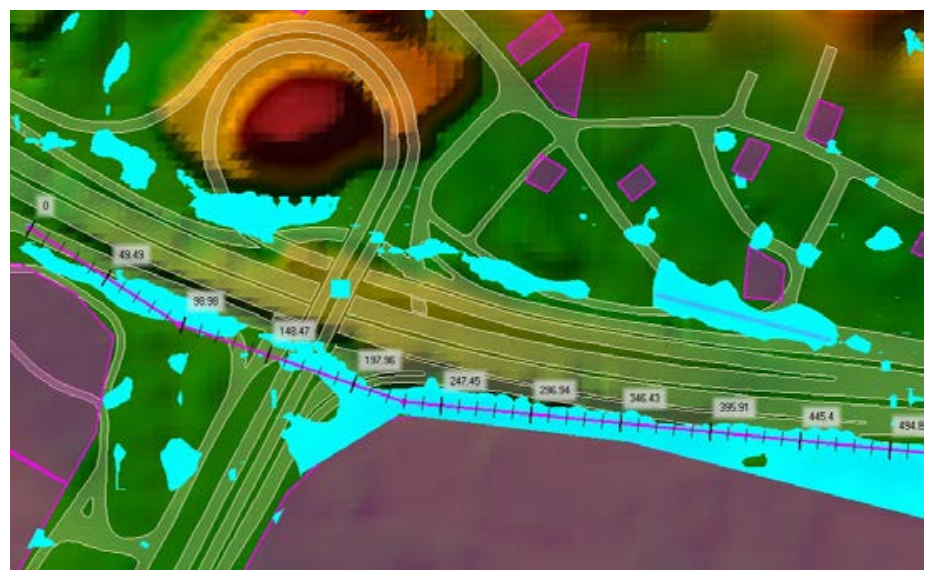

Figure 11 Surface runoff mainly running at the channels between the buildings and street corridor

\section{Scenario Two}

The second scenario was built around a previously planned project. The project of a new road was suggested by the local government; linking two areas to ease traffic congestion. The project was reintroduced by this study and underpinned by special physical measurements to function as drainage channel to bypass runoff water in flooding times. The initial proposal was to link two adjacent watersheds with the route corridor to solve a daily problem of traffic congestion at peak times (07:00-09:00 am and 04:00-06:00 pm).

On the physical level, a topographic analysis was carried out in Arc GIS seeking upstreamdownstream flow pathways. The suggested corridor was set to restore a connection between these two watersheds and end up with a significant natural stream at its far end, which would facilitate runoff conveyance to the coast downstream as planned in the scenario. The proposal 
added the physical value of the road, which increased its feasibility for decision makers. The implementation of this route would help to compensate the natural features lost with the increasing urban sprawl that eroded the hydrological performance of the previous natural landscape.

According to the topography, the route's best alignment was through an old dense residential area in Muscat city. The area is largely dominated by one clan with strong social ties (Figure 12). The local authority had to establish a compensation process to convince those whom properties were affected to leave to a new, better serviced, areas. Most of the residents reject any compensation proposal. The residents valued the place and social life that thrives within the proximity of their neighbourhood more than the cost of the bare building and physical assets. Eventually, even with being a technically sound solution, the project was abandoned to avoid conflict with the community.

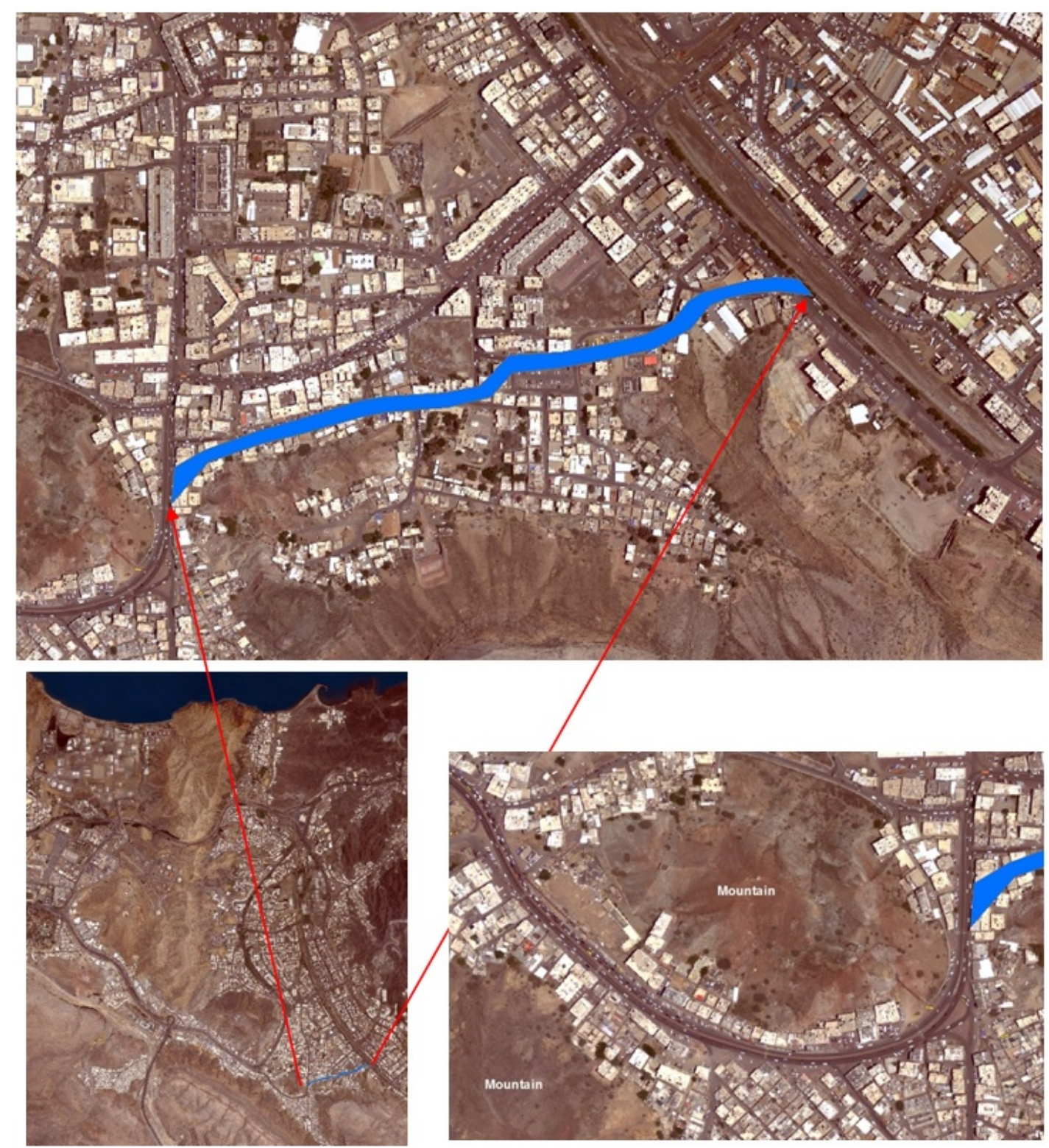

Figure 12 case study area Scenario two

Despite the technically sound solution of Scenario 2, the proposed project was rejected. Scenario 2 shows that adopting resilience surrogates has its own challenges far from the technical aspect that associated with its implementation. Socioeconomic, financial and political 
concerns were more important than the technically viable solutions. in this context, Chang, et al., (2014) affirmed that Research is needed to link urban physical systems with human communities, that support the information and communication needs of infrastructure organisations, and that directly address infrastructure decision-making on an urban and regional scale.

\section{Conclusions:}

By investigating resilience-based solutions to mitigate flood consequences, this article shows the importance and viability of departing from the mode of engineered resistance solutions towards more promising ecological solutions. The process itself of bringing in actual human experience from the boundary of the problem to answer pivotal concerns is itself, opening new pathways to invest and reconcile with the adjacent ecological settings as an influential parameter in flood-prone areas. The socio-economic challenges arose in each area have contextualized the nature of the problem against local circumstances, yet, shaped and adjust the scenarios of looking at the problem solutions.

This article examines two scenarios derived from prioritizing ecological principles in Muscat flood-prone area. The simulation of proposed scenarios showcases the possibility of reducing flood risk by adopting ecologically driven solutions. Scenario 2 , however, shows that proposals that ignore the social and cultural context would fail to be implemented in closely knitted communities. Flood management does require ecological knowledge as it mediates the relationship between human activities and extreme flooding events. A more holistic approach is, therefore, necessary to achieve socially and ecologically sensitive and less expensive mitigation against flood in developing countries.

The problem of flooding was addressed in the article thematically within the tent of Neo Ekistics approach which provides a step change in our approach to resilience, linking ecological principles guided by the social dimensions of human experience. This article provides examples of the resilience value and its trajectories in urban design, moving from the descriptive approach on resilience continuum to the other end of more normative consideration to close down to the measurability of the term.

Finding from both the qualitative and quantitative part of this study concerning the city's resilience revealed the importance of shifting efforts from engineering defence-based solutions towards the effectiveness of ecologically compliant solutions. Resilient cities in developing countries should engage, not only with the ecological principles but also with preparation for the society to take more active leadership and take preventive measures. Current adaptation and mitigation might be plausible where a balance of coupling human and natural systems is still possible. In more extreme cases in flood-prone cities in developing countries; decoupling human and natural systems would be necessary.

The role of resilient urban design to flood is a vast arena with significant potentials that are yet to be explored. The rethinking of urban design as an important tool to maintain resilient status is one of the important goals of this study. The developed scenarios in Muscat City crossexamine resilience perspectives along with urban design essentials. This was done in order to maintain minimum functionality by which an urban context can confidently confront natural threats like flooding without expensive and increasingly unreliable engineering solutions.

\section{Future implications and potentials:}

The previous discussions have revealed an escalating need for a paradigmatic shift, from flooding viewed through the lens of flood control to flood management. The need to accelerate the process of looking for new alternatives is realised by the fact that existing flood control 
infrastructures that guaranteed the safety of cities from flood have failed quite frequently in many places around the world.

Findings from the case study showed that it is worth redirecting some of the annually invested efforts and funding into the perspective of urban resilience as a surrogate approach. This approach can fundamentally be the core of managing the natural threat rather than resisting its impact, an approach of absorbance and persistence rather than targeting resistant-based flood control solutions. This can be clarified in a broader sense through the identification of the differences between the two opposing resistance and resilience strategies.

\section{References}

1. Abdulkareem, M. (2018). The resilience of urban design in mitigating pluvial flood consequences. PhD thesis. The University of Salford

2. Ahern, J. (2011). From fail-safe to safe-to-fail: Sustainability and resilience in the new urban world. Landscape and urban planning 100 (2011) (pp.341-343)

3. Ashley, S. \& Ashley W., 2007. Flood fatalities in the United States.American Meteorological Society, 47(4), pp. 805-818

4. Banholzer, S., Kossin, J., and Donner, S. (2014). "The impact of climate change on natural disasters." Reducing disaster: Early warning systems for climate change, A.Singh and Z.Zommers, eds., Springer, Netherlands, 21-49

5. Bruckner, M., 2012, Climate change vulnerability and the identification of least developed countries, Economic and social affairs, http://www.un.org/en/development/desa/policy/cdp/cdp_background_papers/bp2012 _15.pdf

6. Chang, S. E., McDaniels, J. F., Dhariwal, R., \& Longstaff, H. (2014). Toward DisasterResilient Cities: Characterizing resilience of Infrastructure System with Expert Judgments. Risk Analysis, Vol.34, No.3, 2014. pp. 416-434

7. Conzen, M.R.G. (1960). Alnwick, Northumberland: A Study in Town-Plan Analysis. Retrieved form. URL: jstor.org/stable/621094.

8. Creswell, J. W. 2007. Qualitative inquiry research design. Choosing among five approaches. California; Sage Publication, Inc

9. Davoudi S. (2012) Resilience: a bridge concept or a dead end. Planning Theory \& Practice Vol.13, No2, 299---307

10. Douglas, I. \& James, P. (2015). Urban ecology; An introduction. Oxon. UK. Routledge

11. ElKadi, H., 2015, Rethinking Ekistics: Transformative Approach to Ecological Challenges in Cities, PLEA conference 2015, Bologna, Italy.

12. Fothergill, A., Peek, L.A., 2004. Poverty and disasters in the United States: a review of recent sociological findings. Natural Hazards 32, p. 89-110.

13. Hall, J. W. \& Pennning-Rowsell, E. C. (2011). Setting the Scene for flood reisk management. In, Pender, G. \& Faulkner, H. (2011). (Eds.). Flood Risk Science and Management. Blackwell Publishing Ltd

14. Holling, C. S. (2001) Understanding the complexity of economic, ecological, and social systems. Ecosystems 4: 390-405

15. Houston, D., Werritty, A., Bassett, D., Geddes, A., Hoolachan, A. \& McMillan, M. (2011). Pluvial (rain-related) flooding in urban areas: the invisible hazard. Joseph Rowntree Foundation. UK

16. Huq, S., Reid, H., Konate, M., Rahman, A., Sokona, Y., and Crick, F., 2011, Mainstreaming adaptation to climate change in Least Developed Countries (LDCs), , climate policy, p. 25-43.

17. Liao, K. 2012. A theory on urban resilience to floods-a basis for alternative planning practices. Ecology and Society 17(4) 
18. Miles, M. B., \& Huberman, A. M. (1994). Qualitative data analysis: An expanded sourcebook. Beverly Hills: Sage Publications

19. Mirza, M. M. Q., 2011, Climate change, flooding in South Asia and implications, Regional Environmental Change, 11 (1), pp. 95-107.

20. Ning, L. 2006. From philosophy to action: accomplishing harmonious coexistence between man and flood. Irrigation and drainage: 55: 247-252

21. UNISDR (2009) UNISDR terminology on disaster risk reduction. Geneva, Switzerland

22. White, I. (2008). The absorbent city: urban form and flood risk management. Urban design and planning, 161 December 2008 issue Dp4 (pp. 151-161). DOI: 10.1680/udap.2008.161.4.151

23. Zevenbergen, C., Cashman, A., Evelpidou, N., Pasche, E., Garvin, S., \& Ashley, R. (2011). Urban flood management. London; CRC press 